\title{
EDITORIAL
}

\section{GLOBAL OBESITY AND PAKISTAN}

\author{
Iftikhar Ahmad \\ Department of Community Medicine, Gomal Medical College, D.I.Khan, Pakistan
}

Obesity is rapidly becoming a major public health problem in many parts of the world, including Pakistan. Developed world is viewing a huge switchover from acute and communicable diseases to the chronic and non-communicable diseases. However many developing countries including Pakistan, experience the double burden of communicable and non-communicable diseases. ${ }^{1}$

Globally, the obesity has doubled since 1980. It is prevalent in both developing and developed countries and in children as well as adults, especially women in the urban setting. Besides genetics, increasing urbanization, higher intake of energy-dense foods, changing life-style and sedentariness are the most important determinants, along with socio-economic status and educational level showing inverse relationship with obesity. ${ }^{2}$

Obesity is an abnormal growing adipose tissue due to fat cells size enlargement (hypertrophic) or fat cell number increase (hyperplastic) or both. Android obesity due to abdominal fat distribution is more risky than gynoid obesity having even and peripheral distribution of fats around the body. ${ }^{3}$

Overweight and obesity are the $5^{\text {th }}$ leading threat of global deaths. It has physical, social and psychological consequences. At least 3.4 million adults die each year as a result of being overweight or obese. Obesity as risk factor is associated with hypertension, dyslipidemia, stroke, coronary heart disease, diabetes mellitus, cancer of breast, endometrium and colon, varicose veins, abdominal hernia, osteoarthritis, gall bladder disease, increased risk from surgery, infertility, sleep apnea and respiratory problems. It affects self-esteem, negatively developing cognitive and social aspects resulting in stress in adolescence. It accounts for a significant drop in the quality of life and life expectancy and results in heavy burden on healthcare system. ${ }^{4}$

Childhood obesity has doubled in the last two decades worldwide, including Pakistan with poor understanding of its preventive strategies. It is associated with a higher number of premature deaths and disabilities in adulthood. Substantial political will along with novel approaches in the primary and secondary preventive and curative modalities are required. ${ }^{5,6}$

Obesity is a multifactorial disease. It can present at any age, and generally advances with age. Women gain most at the menopausal age due to progressive weight gain with successive pregnancies, whereas men gain weight a decade or two earlier. Lack of physical activity such as prolonged TV watching, playing computer games for hours, and junk food are the reported risk factors. Obese parents frequently have obese children. Depression and loneliness in childhood may present as obesity due to overeating so is the case with certain drugs. ${ }^{7}$ Eating in between meals, preference for refined foods, carbohydrates and fats result in prolonged post-prandial hyperlipidemia and triglyceride deposition in the adipose tissue causing obesity. Heavy advertisement of fast food outlets of energy-dense, micronutrient-poor foods and beverages of multinational corporations is playing havoc with the lives of people. ${ }^{8}$

WHO classifies body-weight as underweight BMI $<18.5 \mathrm{~kg} / \mathrm{m}^{2}$, normal 18.5-24.99, overweight $\geq 25$, pre-obese 25-29.99, obese (class 1) 30-34.99, obese (class 2) 35-39.99 and obese (class 3 ) $\geq 40$. Accord-

Cite as: Ahmad I. Global obesity and Pakistan [editorial]. Gomal J Med Sci 2020 Apr-Jun: 18(2): 43-4. https:// doi.org/10.46903/gjms/18.02.831

\section{Corresponding Author:}

Professor Iftikhar Ahmad

Department of Community Medicine

Gomal Medical College

D.I.Khan, Pakistan

E-mail: iftikharahmadgandapur66@gmail.com

$\begin{array}{ll}\text { Date Submitted: } & 04-01-2020 \\ \text { Date Revised: } & 18-02-2020 \\ \text { Date Accepted: } & 01-03-2020\end{array}$ ing to WHO Expert Committee, 1995, weight within BMI 18.5-24.9 throughout adulthood and prevention of weight gain of $>5 \mathrm{~kg}$ should be the aim. As an initial goal, $5-10 \%$ reduction in over-weight people is recommended. Diet with suitable proportion of cereals, legumes, vegetables and fiber at the cost of simple carbohydrates and fats with intake lesser than energy expenditure, needs strong motivation and modification of behavior otherwise most dieting attempts remain unsuccessful. The physical activity should be kept at higher level through different lei- 
sure activities such as gardening, dancing, cycling, swimming, walking, running, yoga exercises and occupational and household work. The vicious circle of reduced physical activity- obesity- restricted activity- more obesity needs to be broken. Motorized transport, washing machines, automated lift instead of stairs, etc. should be discouraged. Bariatric surgeries such as gastroplasty, gastric bypass, jaw-wiring are highly successful in producing remission of complications by dissolving subcutaneous fats. ${ }^{9,10}$

Prevention of obesity may reduce the suffering, disability and death and timely obesity prevention programs in the developing countries are the need of the day.

\section{REFERENCES}

1. Tanzil S, Jamali T. Obesity, An Emerging Epidemic In Pakistan-A Review Of Evidence. J Ayub Med Coll Abbottabad 2016 Jul-Sep; 28(3):597-600.

2. Nanan DJ. The obesity pandemic--implications for Pakistan. J Pak Med Assoc 2002 Aug; 52(8):342-6.

3. Park K. Parks Textbook of Preventive and Social Medicine, 22nd ed. Jabalpur: Banarsidas Bhanot; 2006. p. 459-77.

4. Gupta MC, Mahajan BK. Textbook of Preventive and Social Medicine, 3rd ed. New Delhi: Jaypee Brothers; 2003. p. 66 -80. https://doi.org/10.5005/ jp/books/10951_8

5. Afzal MN, Naveed M. Childhood obesity and Pakistan. J Coll Physicians Surg Pak 2004 Mar; 14(3):189-92. Erratum in: J Coll Physicians Surg
Pak 2004 May; 14(5):326.

6. Lowry R, Galuska DA, Fulton JE, Wechsler H, Kann L, Collins JL. Physical activity, food choice, and weight management goals and practices among US college students. Am J Prev Med 2000 Jan; 18(1):18-27. https://doi.org/10.1016/ S0749-3797(99)00107-5

7. Mistry SK, Puthussery S. Risk factors of overweight and obesity in childhood and adolescence in South Asian countries: a systematic review of the evidence. Public Health 2015 Mar; 129(3):2009. doi: 10.1016/j.puhe.2014.12.004 https://doi. org/10.1016/j.puhe.2014.12.004

8. Lewis M, Hill A. Food advertising on British children's television: a content analysis and experimental study with nine-year olds. Int J Obes 1998; 22:206-14. https://doi.org/10.1038/sj.ijo.0800568

9. Mushtaq MU, Gull S, Abdullah HM, Shahid U, Shad MA, Akram J. Prevalence and socioeconomic correlates of overweight and obesity among Pakistani primary school children. BMC Public Health 2011 Sep 25; 11:724. https://doi. org/10.1186/1471-2458-11-724. Erratum in: BMC Public Health 2012; 12:532. https://doi. org/10.1186/1471-2458-12-532

10. Shah AA, Shariff AH. Obesity and the need for bariatric surgery in Pakistan. Asian J Endosc Surg 2013 Nov; 6(4):257-65. https://doi.org/10.1111/ ases. 12048

11. Jenkins CD. Building Better Health: A Handbook of Behavioral Change. Scientific and Technical Publication No. 590. Washington D.C: Pan American Health Organization 2003.

CONFLICT OF INTEREST

Authors declare no conflict of interest. GRANT SUPPORT AND FINANCIAL DISCLOSURE None declared. 